\title{
Body Perception and Self-Esteem in Individuals Performing a Bodybuilding Exercise Program
}

\section{Vücut Geliştirme Egzersiz Programı Uygulayan Bireylerde Beden Algisı ve Benlik Saygısı}

\author{
Yıldız Erdoğanoğlu1 ${ }^{1}$ Ünzile Tunç² \\ ${ }^{1}$ Department of Physiotherapy and Rehabilitation, Faculty of Health Sciences, Üsküdar University, İstanbul, Turkey \\ ${ }^{2}$ Yeni Bakış Special Training and Rehabilitation Center, İstanbul, Turkey
}

Y. Erdoğanoğlu (D)
0000-0002-9909-6561
Ü. Tunç (D)
0000-0001-8454-8046

Geliş Tarihi/Date Received: 30.01.2019

Kabul Tarihi/Date Accepted: 07.08.2019

Yayın Tarihi/Published Online: 03.12.2019

Yazışma Adresi /

Corresponding Author:

Yildız Erdoğanoğlu

Üsküdar Üniversitesi, Sağlık Bilimleri Fakültesi, Fizyoterapi ve Rehabilitasyon Bölümü, İstanbul, Turkey

E-mail:

yildiz.erdoganoglu@uskudar.ed u.tr

(C)2020 Türkiye Spor Hekimleri Derneği. Tüm hakları saklıdır.

\section{ABSTRACT}

Objective: The aim of this study was to determine the relationship of body, upper extremity, lower extremity endurances and core functionality with body perception and self-esteem in individuals who continued a body building exercise program.

Materials and Methods: Forty volunteer male subjects who underwent bodybuilding exercises for one year or more were included in the study. After obtaining personal information of the individuals, trunk endurance was evaluated by curl-up and modified Sorensen test, upper extremity endurance by push-up test, lower extremity endurance by repeated squat test, core functionalities by single leg wall sitting and repeated single leg squatting tests. Body perception and self-esteem were evaluated with Body Image Perception and Rosenberg Self-Esteem scales, respectively.

Results: Mean age of the individuals was $25.6 \pm 4.7 \mathrm{yrs}$, mean exercise time was 22.5 \pm 34.6 months. At the end of the study, body perception was low and self-esteem was moderate. There were no significant relationships between abdominal extensor, back extensor, upper extremity and lower extremity endurances, core functionalities and both body perception and self-esteem evaluations ( $p>0.05$ ).

Conclusion: The body, upper and lower extremity endurances and core functionality of bodybuilders did not have any effect on body perception and self-esteem, suggesting that their programs did not contribute positively to their efforts to improve their body perception and self- esteem.

Keywords: Body perception, self-esteem, body endurance, core muscle functionality

\section{öz}

Amaç: Bu çalışmanın amacı, vücut geliştirme egzersizi uygulayan bireylerde gövde, üst ekstremite, alt ekstremite dayanıklıı̆̆ı ve gövde merkezi (kor) kas işlevselliğinin beden algısı ve benlik saygısı ile ilişkisini araştırmaktır.

Gereç ve Yöntemler: Çalışmaya bir yıl ve üzeri vücut geliştirme egzersizi uygulayan 40 gönüllü erkek birey alındı. Bireylerin özellikleri kaydedildikten sonra, gövde dayanıklılıkları mekik ve modifiye Sorensen testi ile, üst ekstremite dayanıklılıkları şınav testi ile, alt ekstremite dayanıklılıkları tekrarlı skuat testi ile, kor kas işlevsellikleri tek bacak duvar oturuşu ve tekrarlayan tek bacak çömelme testleri ile değerlendirildi. Bireylerin beden algıları Vücut Algısı Ölçeği ile, benlik saygıları ise Rosenberg Benlik Saygısı Öıçeği ile değerlendirildi.

Bulgular: Bireylerin yaş ortalaması $25.6 \pm 4.7 \mathrm{yıl}$, egzersiz yapma süre ortalamaları ise $22.5 \pm 34.6$ aydı. Çalışma sonucunda bireylerin beden algıları düşük, benlik saygıları ise orta düzeyde bulundu. Bireylerin abdominal dayanıklılığı, sırt ekstansör dayanıklıı̆̆ı, 
üst ekstremite ve alt ekstremite dayanıklıığı, kor kasları işlevselliği ile beden algısı ve benlik saygısı değerlendirmeleri arasında anlamlı ilişki bulunmadı ( $p>0.05)$.

Sonuç: Vücut geliştirme egzersizi yapan bireylerin gövde, üst ve alt ekstremite dayanıklılıkları ve kor bölgesi kas işlevselliklerinin beden algısı ve benlik saygısına anlamlı bir katkı sağlamadığı belirlenmiştir.

Anahtar sözcükler: Vücut algısı, benlik saygısı, vücut dayanıklılığı, kor kasları işlevselliği

Available at: http://journalofsportsmedicine.org and http://dx.doi.org/10.5152/tjsm.2020.163

Cite this article as: Erdoganoglu $\mathrm{Y}$, Tunc U. Body perception and self-esteem in individuals performing a bodybuilding exercise program. Turk J Sports Med. 2020;55(2):79-85.

\section{GíRIŞ}

Beden görünümü son yıllarda üzerinde sıklıkla durulan bir konu haline gelmiştir (1). İnsanların bedenlerinden hoşnut olmalarının temeli bedenlerini nasıl algıladıklarına bağlıdır. Kişilerin bedenlerini algılama düzeyleri bazen bedenleri ile uyumlu iken, bazen çok farklı olabilmektedir. Araştırmalar spora katılımın beden algısını olumlu yönde etkilediğini göstermektedir (2-6).

Anatomik ve fonksiyonel olarak bedenin ağırlık merkezinin vücudun en etkileyici bölümü olması, hareket için stabilite sağlaması ve vücudun üst yarısı ile alt yarısı arasında güç aktarımından sorumlu olması kor bölgesine ait antrenmanların önemini artırmaktadır (7-10). Kor bölgesi kuvvet egzersizleri; koşu ekonomisini geliştirme, anaerobik kapasiteyi arttırma, maksimal hızı geliştirme, yorgunluğu geciktirme ve dayanıklılık performansını yükseltme gibi yollarla spor performansını arttırmaya katkı sağlamaktadır (8). Kor antrenmanları ile vücudun kontrolü ve dengesi gelişir, birçok büyük ve küçük kas grubunun kuvveti artar, yaralanma riski azalır ve denge artışına bağlı olarak hareketler veya hareketler arasındaki geçişlerdeki verimlilik $\operatorname{artar}(7,9,11)$.

Literatürde farklı egzersiz türlerine ait beden algısı ve benlik saygısına etkisini gösteren çalışmalar olduğu halde, vücut geliştirme egzersizi yapan bireylerde beden algısı ve benlik saygısını değerlendiren sınırlı sayıda çalışma vardır $(12,13)$. Vücut geliştirme sporu hem fiziksel performans hem de kozmetik yönü olan bir spor türüdür. Bilgilerimiz dâhilinde dayanıklılık ve kor kasları işlevselliğinin beden algısı ve benlik saygısı ile olan ilişkisini inceleyen bir çalışma da bulunmamaktadır. Bu nedenle bu çalışma, vücut geliştirme egzersiz programı uygulayan bireylerin gövde, üst ve alt ekst- remite dayanıklılığı ve kor kasları işlevselliğinin beden algısı ve benlik saygısı ile olan ilişkisini araştırmak amacıyla planlandı.

\section{GEREÇ VE YÖNTEMLER}

Çalışma 2018 yılında, İstanbul ilinde özel bir spor salonunda gerçekleștirildi. Çalışmanın gerçekleştirilebilmesi için öncesinde gerekli etik kurul izini alındı (Üsküdar Üniversitesi Girişimsel Olmayan Etik Kurulu B.08.6.YÖK.2.ÜS.0.05.0.06/2018/435

23.02.2018 tarihli 2 No'lu Karar). Bu araştırma Helsinki Deklarasyonuna uygun olarak gerçekleştirildi ve çalışmaya katılan gönüllülerin yazılı onamları alındı.

Katılımcılar: Çalışmanın örneklemini, 18-35 yaş aralığında, en az bir yıldır üst-alt ekstremite ve gövde kaslarına yönelik amatör olarak vücut geliştirme egzersiz programı uygulayan 40 gönüllü erkek birey oluşturdu. Bireylerin egzersiz programları fitness eğitmenleri tarafından kişisel olarak düzenlenmiş programlardı. Bireylere uygulanan egzersiz programları iki aylık dönemler halinde izlenmekte ve kişinin fiziksel gelişimine göre üzerinde değişiklikler yapılmaktaydı. Çalışmaya katılan 40 bireyden 17'si her egzersiz seansında tek vücut bölgesine yönelik olarak; yüksek yoğunluklu, tekrar sayısı az, haftada 5-6 gün olacak şekilde düzenlenmiş bir program izlemişti. Diğer 23 birey ise her egzersiz seansında çift vücut bölgesine yönelik yoğunluğu düşük, tekrar sayısı fazla birer gün aralıklarla olacak şekilde haftada 3-4 gün düzenlenmiş egzersiz programı uygulamaktaydı. Metabolik hastalığın olması, tendinopati varlığı, travmatik kasiskelet yaralanması geçirilmiş olması, üst ve alt ekstremitede herhangi bir cerrahi girişim geçirilmiş olması, mekanik bel ağrısı tanısı alınmış 
olması, solunum yolu hastalığı ve herhangi bir nörolojik hastalığın varlığı çalışma dişı bırakılma ölçütü olarak belirlendi. Bütün değerlendirmeler aynı fizyoterapist tarafından yapıldı.

\section{Ölçümler}

Üst ekstremite dayanıklılığı: Üst ekstremite dayanıklılığı, bir dakikalık şınav testi ile değerlendirildi. Testte, başlangıçta bireylerden mat üzerine yüz üstü ve kollar gergin dirsekler düz pozisyonda iken, elleri yerle temas halinde aynı yöne bakacak şekilde ve omuz genişliğinde açlk, diz yerle temas halinde pozisyon alması istendi. Sonrasında ise baştan dize kadar düz bir çizgi halinde, dirseklerini $90^{\circ}$ bükerek yere yaklaşmaları ve vücut pozisyonu bozulmadan başlangıca dönmeleri istendi. Test başlangıçta kişilere gösterilerek anlatıldı ve bir dakika boyunca dinlenme olmadan art arda gerçekleştirilen maksimum şınav sayısı kaydedildi. Üç deneme yapılarak ortalaması alındı (14).

Alt ekstremite dayanıklılı̆g: Alt ekstremitenin dayanıklılığı, bir dakikadaki maksimum skuat sayısı ile test edildi. Testte, bireylerden ayaklar omuz genişliğinde açık, sırt düz ve kollar öne doğru uzanmışken, üst bacaklar yerle paralel olana kadar dizlerini büküp tekrar başlangıç pozisyonuna gelmeleri istendi. Test başlangıçta bireylere gösterilerek anlatıldı ve bir dakika boyunca dinlenme olmadan gerçekleştirilen maksimum skuat sayısı kaydedildi. Üç deneme yapılarak ortalaması kaydedildi (15).

Abdominal dayanıklılı: Abdominal dayanıklılı, bir dakikadaki maksimum mekik sayısı ile değerlendirildi. Testte bireyler, başlangıçta sırt üstü yatış pozisyonunda, dizler yaklaşık $140^{\circ}$ bükülü, ayak düz ve zeminde, bacaklar hafifçe birbirinden ayrık, kollar düz, avuç içleri ve parmaklar gergin ve başparmak ile temas halinde iken uzandılar. Ölçüm şeridi, bireylerin bacaklarının altındaki mata yerleștirildi ve parmak uçları ölçüm şeridinin gövdeye en yakın bölümünde tutuldu. Bireyler, test esnasında başlangıçta ayaklarını mat ile temas halinde tutup, parmaklarını diğer uca gelinceye kadar ölçme şeridi boyunca kaydırarak, yavaşça yukarı doğru kıvırdılar ve baş tekrar mata değecek şekilde başlangıç pozisyonuna döndüler. Test başlangıçta gösterilerek anlatıldı ve bir dakikada gerçekleştirilen maksimum mekik sayısı kaydedildi. Üç deneme yapılarak ortalaması alındı (11).

Sırt ekstansör kaslarının dayanıklılı̆g: Sırt ekstansör kaslarının dayanıklılığı, bir dakikadaki maksimum modifiye Sorensen testi ile değerlendirildi. Testte başlangıçta bireyler, masanın kenarıyla hizalı olarak, iliyak kristalarının üst çıkıntıları masaya temas edecek şekilde yattılar. Alt gövde sırasıyla pelvis, dizler ve ayak bileği etrafında üç kemerle masaya sabitlendi. Sonrasında bireyler gövdeyi öne eğerek desteksiz kalktılar. Test başlangıçta gösterilerek anlatıldı ve bir dakika boyunca gerçekleştirilen sayı kaydedilerek, üç denemenin ortalaması alındı (16).

Kor kaslarının işlevselliği: Kor kaslarının işlevselliği, tek bacak duvar oturuşu testi ve tekrarlayan tek bacakla çömelme testi ile değerlendirildi. Her iki test de sağ ve sol iki taraflı olarak yapıldı. Tek bacak duvar oturuşu testinde, bireyler sirtları duvara yaslı iken, $90^{\circ}$ diz ve kalça fleksiyonu yaparak bir bacak serbest kalacak şekilde kaldırdı ve bu pozisyonu koruyabildikleri maksimum süre kaydedildi. Test başlangıçta gösterilerek anlatıldı ve üç deneme yapılarak ortalama süre kaydedildi (17).

Tekrarlayan tek bacakla çömelme testinde bireyler, dik pozisyonda, tek bacak üzerinde $60^{\circ}$ diz fleksiyonu ve $65^{\circ}$ kalça fleksiyonu pozisyonuna gelene kadar çömeldiler ve tekrar başlangıç pozisyonuna döndüler. Test başlangıçta gösterilerek anlatıldı ve pozisyon korunduğu sürece gerçekleştirilen maksimum tekrar sayısı kaydedildi. Üç deneme yapılarak ortalaması alındı (17).

\section{Vücut Algısı Ölçeği}

Bireylerin beden algıları, Vücut Algısı Ölçeği (VAÖ) ile değerlendirildi. VAÖ, 1953 yılında Secord ve Jourand tarafından geliștirilmiş (18), 1989 yılında Hovardaoğlu tarafından Türk toplumuna uyarlanmıştır (19). Ölçek, 40 madde içermekte olup her bir madde bir organ ya da vücudun bir bölümü (kol, bacak, yüz gibi) ya da bir işlevi (cinsel faaliyet düzeyi gibi) ile ilgilidir. 
Ölçekten alınabilecek toplam puan 40 ile 200 arasında değişmekte olup, alınan puanın yüksekliği doyum düzeyinin yüksekliğini gösterir. Çalışmada bireylerden kendilerine uygun seçeneği işaretlemeleri istendi ve toplam puan hesapland.

\section{Rosenberg Benlik Saygısı Ölçeği}

Bireylerin benlik sayglları, Rosenberg Benlik Saygısı Ölçeği (RBSÖ) ile değerlendirildi. RBSÖ, Rosenberg (20) tarafından 1963 yılında geliștirilmiş ve on iki alt alandan oluşan ve ilk on maddesi benlik saygısını ölçen bir ölçektir. RBSÖ'nün Türkiye için güvenilirlik ve geçerlilik çalışmaları Çuhadaroğlu (1986) tarafından yapılmıştır (21). Ölçekte, 0-1 puan yüksek benlik saygısı, 2-4 puan orta benlik saygısı, 5-6 puan düşük benlik saygısını gösterir. Çalışmada bireylerden kendilerine uygun seçeneği işaretlemeleri istendi ve toplam puan hesapland.

İstatistiksel analiz: Verilerin istatistiksel değerlendirmesi, SPSS 22.0 istatistik programı kullanılarak yapıldı. Araştırma kapsamında minimum örneklem büyüklüğünü belirlemek amacıyla güç analizi yapıldı. Analizi yapmak için G Power 3.0.10 programı kullanıldı. Böylece 0.05 hata ve 0.95 güvenirlik düzeyi için ulaşılması gereken minimum örneklem büyüklüğü 36 olarak hesaplandı. Sayısal özelliklerin normal dağılım gösterip göstermediği Kolmogorov-Smirnov ve Shapiro Wilks testi, Skewness değerleri ve Kurtosis değerleri ile incelendi. Sayımla belirtilen değişkenler sayı ve yüzde olarak verildi. Verilerin istatistiksel gösterimlerinde, aritmetik ortalama, standart sapma, minimum ve maksimum değerleri sunuldu. Elde edilen verilerle Spearman korelasyon analizi yapıldı. Anlamlılık düzeyi $\mathrm{p}<0.05$ olarak kabul edildi.

\section{BULGULAR}

Çalışmaya katılan bireylerin tanımlayıcı özellikleri Tablo 1'de gösterilmektedir.

Bireylerin öğrenim ve alışkanlık durumları (sayı, $\%)$ ilköğretim $(1,2.5 \%)$, lise $(11,22.5 \%)$, ön lisans $(6,1.5 \%)$, lisans $(17,42.5 \%)$; sigara kullananlar $(14,35.0 \%)$, alkol kullananlar $(3,7.5 \%)$, sigara ve alkol kullananlar $(23,57.5 \%)$ şeklindeydi.

Tablo 1. Bireylerin tanımlayıcı verileri

\begin{tabular}{|c|c|c|}
\hline & Ortalama \pm SS & $\begin{array}{l}\text { En küçük-en } \\
\text { büyük }\end{array}$ \\
\hline Yaş & $25.6 \pm 4.7$ & $18.0-35.0$ \\
\hline Boy (cm) & $177.9 \pm 5.9$ & $166.0-189.0$ \\
\hline Ağırlık (kg) & $77.2 \pm 7.7$ & $63.0-96.0$ \\
\hline VKİ (kg/m²) & $24.5 \pm 2.3$ & 18.8-33.6 \\
\hline $\begin{array}{l}\text { Antrenmana } \\
\text { katılım süreleri } \\
\text { (ay) }\end{array}$ & $22.5 \pm 34.6$ & $12.0-216.0$ \\
\hline $\begin{array}{l}\text { Antrenman } \\
\text { frekansı } \\
\text { (gün/hf) }\end{array}$ & $4.3 \pm 0.9$ & $2.0-6.0$ \\
\hline
\end{tabular}

VKİ: vücut kitle indeksi; SS: Standart Sapma; $n=40$

Çalışmaya katılan bireylerin VAÖ sonuçları düşük, RBSÖ sonuçları ise orta düzeyde bulundu. Kullanılan değerlendirme yöntemlerinin tanımlayıcı istatistikleri Tablo 2'de gösterilmektedir.

Tablo 2. Değerlendirme yöntemlerinin tanımlayıcı verileri

\begin{tabular}{|c|c|}
\hline Değerlendirme yöntemleri & $\begin{array}{l}\text { Tanımlayıcı } \\
\text { istatistikler }(n=40)\end{array}$ \\
\hline Abdominal dayanıklılık & $41.0 \pm 2.7$ \\
\hline $\begin{array}{l}\text { Sirt ekstansör kaslarının da- } \\
\text { yanıklılığı }\end{array}$ & $30.6 \pm 2.0$ \\
\hline Üst ekstremite dayanıklılığı & $35.9 \pm 2.4$ \\
\hline Alt ekstremite dayanıklılığı & $30.8 \pm 2.2$ \\
\hline \multicolumn{2}{|l|}{ Kor kaslarının işlevselliği } \\
\hline $\begin{array}{l}\text { Tek bacak duvar oturuşu (sağ ba- } \\
\text { cak) }\end{array}$ & $39.8 \pm 4.8$ \\
\hline $\begin{array}{l}\text { Tek bacak duvar oturuşu (sol ba- } \\
\text { cak) }\end{array}$ & $36.5 \pm 4.4$ \\
\hline Tek bacakla çömelme (sağ bacak) & $11.7 \pm 2.0$ \\
\hline Tek bacakla çömelme (sol bacak) & $10.1 \pm 1.8$ \\
\hline Vücut Algısı Ölçeği & $65.5 \pm 18.9$ \\
\hline Rosenberg Benlik Saygısı Ölçeği & $4.08 \pm 0.99$ \\
\hline
\end{tabular}


Bireylerin üst ekstremite, alt ekstremite ve gövde kaslarının dayanıklılığı ile beden algıları ve benlik saygıları arasında anlamlı bir ilişki bulunmadı ( $p>0.05)$, (Tablo 3). Yine bireylerin kor bölgesi kas işlevselliklerine yönelik yapılan tek bacak duvar oturuşu testi ve tekrarlayan tek bacakla çömelme testinin hem sağ hem sol alt ekstremite verileri ile beden algıları ve benlik saygıları arasında anlamlı ilişki bulunmadı ( $>$ >0.05), (Tablo 3).

Tablo 3. Dayanıklılık ve kor kasları işlevselliği ile Vücut Algısı ve Benlik Saygısı arasındaki ilişkiler

\begin{tabular}{lllll}
\hline Değerlendirme Yöntemleri & & VAÖ & \multicolumn{2}{c}{ RBSÖ } \\
\hline Üst ekstremite dayanıklılığı & $\mathrm{r}$ & $\mathrm{p}$ & $\mathrm{r}$ & $\mathrm{p}$ \\
\hline Alt ekstremite dayanıklılı̆̆ı & 0.037 & 0.823 & 0.073 & 0.654 \\
\hline Abdominal dayanıklılık & 0.122 & 0.452 & 0.219 & 0.175 \\
\hline Sırt ekstansör kaslarının dayanıklılı̆̆ı & 0.020 & 0.902 & 0.065 & 0.690 \\
\hline Kor kasları işlevselliği & & & & 0.099 \\
\hline Tek bacak duvar oturuşu (sağ bacak) & -0.067 & 0.681 & -0.062 & 0.705 \\
\hline Tek bacak duvar oturuşu (sol bacak) & -0.108 & 0.507 & 0.059 & 0.718 \\
\hline Tek bacakla çömelme (sağ bacak) & -0.017 & 0.919 & 0.069 & 0.674 \\
\hline Tek bacakla çömelme (sol bacak) & 0.120 & 0.462 & 0.042 & 0.797
\end{tabular}

Spearman korelasyon analizi, p<0.05; VAÖ: Vücut Algısı Ölçeği; RBSÖ: Rosenberg Benlik Saygısı Ölçeği

\section{TARTIŞMA}

Çalışma koşullarından dolayı zorunlu olarak insanları inaktiviteye yönlendiren modern yaşam sağlığı olumsuz etkilemektedir. Bu nedenle günümüzde insanların aktif yaşamlarını daha sağlıklı ve kaliteli bir şekilde sürdürebilmeleri için egzersiz yapmaları gerekmektedir. Düzenli yapılan egzersizin pek çok hastalık riskini azalttığı, psikolojik olarak rahatlattığı ve kişilerin bedenlerini daha iyi hissetmelerini sağladığı artık herkes tarafından kabul edilen bir gerçektir (22). Egzersiz yapmanın en önemli getirilerinden biri de fiziksel görüntüdeki kozmetik düzelme ve dolayısıyla toplumsal kabul görme düzeyinin yükselmesidir (13). Egzersiz tipleri zaman zaman güncel eğilimlerle değişimler gösterse de temel amaç beden algısı ve benlik saygısının kazanılmasıdır (1).

Benlik saygısı cinsiyete göre farklılık gösterdiği için, sadece erkek bireyler değerlendirmeye alınarak çalışmada homojenite sağlanmıştır. Tiggemann ve Williamson (23), sedanter birey- lerde egzersizle benlik saygısı arasında erkekler için pozitif, kadınlar için ise negatif anlamlı bir ilişki olduğunu göstermiştir. Başka bir çalışmada erkek üniversite öğrencilerinin benlik saygısı kadın öğrencilerin benlik saygısından yüksek bulunmuştur (24). Aşçı (25), fiziksel benlik algısı açısından erkeklerin kadınlardan daha yüksek puanlarının olduğunu göstermiştir.

Bu çalışmada aktif olarak bir yılın üzerinde amatör vücut geliştirme egzersizi yapan erkeklerin üst ve alt ekstremite dayanıklılığı, gövde kaslarının dayanıklılığı ve kor bölgesi kas işlevselliğinin beden algısı ve benlik saygısına etkileri incelendi. Bulunan değerler literatürdeki aynı yaş grubu ortalama değerlerinden daha yüksekti (26). Buna rağmen çalışmaya katılan bireylerin beden algılarının düşük, benlik saygılarının ise orta düzeyde olduğu bulundu. Diğer yandan bireylerin dayanıklılık testi sonuçları ile beden algısı ve benlik saygısı arasında da anlamlı bir ilişki bulunmadı. Bizim sonuçlarımızdan farklı olarak birçok çalışmada fiziksel görünümleri ile 
ilgili olumsuz duygu ve düşünceleri bulunan bireylere uygulanan egzersiz programlarının beden algısı ve benlik saygısı üzerinde etkili olduğu gösterilmiştir $(27,28)$.

Egzersiz programları, benlik saygısı üzerinde anlamlı ölçüde artışa öncülük eder $(23,28,29)$. İçten ve ark. (30) altı hafta uygulanan egzersiz programı ile çocuklarda benlik kavramı ve benlik saygısında olumlu iyileșme sağlandığını göstermiştir. Ayrıca aerobik egzersiz, kuvvet antrenmanı ve kombine aerobik-kuvvet antrenmanı gibi farklı egzersiz uygulamalarının benlik saygısı üzerinde eșit derecede olumlu etkisi olduğu bilinmektedir (31). Kamal ve ark. (32) sporcular ile sporcu olmayanların benlik saygılarını irdelemiş ve sporcuların sporcu olmayanlara göre anlamlı derecede yüksek benlik saygısına sahip olduklarını gözlemiştir. Pickett ve ark. (33) erkeklerde kas ve beden imajını incelemiş, elit ve amatör vücut geliștiricilerin diğer aktif bireylere oranla daha çok görünüş değerlendirme skoruna sahip olduklarını belirlemiștir.

Bununla birlikte, bu çalışmadakine benzer olarak lise öğrencilerinde spor etkinliklerine katılmanın benlik saygısını arttırdığı, fakat anlamlı bir fark yaratmadığı bulunmuştur (34). Çiçek ve ark. (35) da sedanter kadınlarda 12 hafta süreyle uygulanan kardiyo ve Bosu egzersizlerinin benlik algısını yükseltmekle birlikte anlamlı bir fark oluşmadığını bildirmiştir. Başka bir çalışmada ise sedanter genç bireylerde yüksek yoğunluklu interval ve sürekli submaksimal egzersiz uygulamalarının benlik saygısına etki etmediği gösterilmiştir (36).

Profesyonel sporcularda anksiyete düzeyinin yüksek olabildiği, özellikle de yoğun antrenman dönemlerinde depresif belirtilerin ve kronik yorgunluk belirtilerinin ortaya çıkabildiği gösterilmiştir (37). Bu çalışmanın bir sınırlılığı, vücut geliştirme egzersiz programı uygulayan bireylerde anksiyete, depresyon, kaygı gibi parametrelerin beden algısı ve benlik saygisı ile olan ilişkilerinin değerlendirilmemiş olmasıdır.

Sonuç olarak; vücut geliştirme egzersizi yapan bireyler de dâhil olmak üzere, günümüzde egzersizle ilgili beklentiler daha çok sağlığ koru- ma yönündedir. Ayrıca insanların beden görünümlerinden memnun olma durumu farklı sosyokültürel etkenlerin oluşturduğu psikolojik bir algıdır ve farklı yansımaları söz konusu olabilir. Ancak egzersiz yapılmadığında oluşabilecek fiziksel sorunların özellikle iş yaşamını olumsuz etkileme riski, zaman zaman beden algısı kavramının önüne geçebilmektedir. Bu noktada, egzersiz yapma alışkanlığı ve egzersiz tipi incelemelerinin yanı sıra duygu-durum ve sosyoekonomik parametrelerle ilişkilendirilecek çalışmaların konuya farklı bir bakış açısı kazandıracağı düşünülmüştür.

\section{KAYNAKLAR}

1. Tylka TL, Wood-Barcalow NL. What is and what is not positive body image? Conceptual foundations and construct definition. Body Image. 2015;14:118-29.

2. Grogan S. Body image and health. J Health Psychol. 2006;11(4):523-30.

3. Erşan EE, Doğan 0 , Doğan S. Beden eğitimi ve antrenörlük bölümü öğrencilerinde benlik saygısı düzeyi ve bazı sosyodemografik özelliklerle ilişkisi. $J$ Clin Psy. 2009;12(1):35-42.

4. Tok S, Güneş İ, Koyuncu M, et al. The effect of female media body images on body image dissatisfaction in female athletes and nonathletes. Türkiye Klinikleri J Med Sci. 2011; 31(5):1049-56.

5. Kong $\mathrm{P}$, Harris LM. The sporting body: body image and eating disorder symptomatology among female athletes from leanness focused and nonleanness focused sports. J Psychol. 2015;149(1-2): 141-60.

6. Schubert A, Januário RS, Casonatto J, et al. Body image, nutritional status, abdominal strength, and cardiorespiratory fitness in children and adolescents practicing sports. Rev Paul Pediatr. 2013;31(1):71-6.

7. Bliss LS, Teeple P. Core stability: the centerpiece of any training program. Curr Sports Med Rep. 2005;4(3):179-183.

8. Stephenson J, Swank AM. Core training: designing a program for anyone. Strength Cond J. 2004;26(6):34-7.

9. Rivera CE. Core and lumbopelvic stabilization in runners. Phys Med Rehabil Clin N Am. 2016;27(1):31937.

10. Rønnestad BR, Mujika I. Optimizing strength training for running and cycling endurance performance: a review. Scand J Med Sci Sports. 2014;24(4):603-12.

11. Sekendiz B, Cuğ M, Korkusuz F. Effects of Swiss-ball core strength training on strength, endurance, flexibility, and balance in sedentary women. J Strength Cond Res. 2010;24(11):3032-40.

12. Pickett TC, Lewis RJ, Cash TF. Men, muscles, and body image: comparisons of competitive bodybuilders, 
weight trainers, and athletically active controls. $\mathrm{Br} J$ Sports Med. 2005;39(4):217-22.

13. Olivardia R, Pope HG Jr, Borowiecki III JJ, et al. Biceps and body image: the relationship between muscularity and self-esteem, depression, and eating disorder symptoms. Psychol Men Masc. 2004;5(2):112-20.

14. Ambegaonkar JP, Caswell SV, Winchester JB, et al. Upper-body muscular endurance in female universitylevel modern dancers: a pilot study. J Dance Med Sci. 2012;16(1):3-7.

15. Kutlu M, Karadağ A. Futbolcularda baskın olan ve olmayan bacakların kuvvet, güç, sürat ve esnekliğinin yeni geliștirilmiş metotlarla belirlenmesi. Gazi BESBD. 2003;8(2):33-42.

16. Aydoğan Arslan S, Erbahçeci F. Bel ağrısında farklı fizyoterapi programlarının ağrı, endurans ve yaşam kalitesi üzerine etkinliği. Firat Med J. 2016;21(2):8490.

17. Chimera NJ, Knoeller S, Cooper R, et al. Prediction of functional movement screen ${ }^{\mathrm{TM}}$ performance from lower extremity range of motion and core tests. Int $J$ Sports Phys Ther. 2017;12(2):173-81.

18. Secord PF, Jourard SM. The appraisal of body-cathexis: body-cathexis and the self. $J$ Consult Psychol. 1953;17(5):343-47.

19. Hovardaoğlu S. Vücut algısı ölçeği. Psikiyatri, Psikoloji, Psikofarmakoloji Dergisi (3P). 1993; 1(Testler Özel Eki):26-7.

20. Rosenberg M. Society and the Adolescent Self-Image. Princeton University Press: Princeton, NJ; 1965.

21. Çuhadaroğlu Çetin F. Gençlerde benlik saygısı ile ilgili bir araştırma. XXI. Ulusal Psikiyatri ve Nörolojik Bilimler Kongresi; 1985; Mersin, Türkiye. Kongre Kitabı s. 107-8;1986.

22. Kale R. Yaşam Boyu Spor-Sağlık, Egzersiz, Terapi. Birinci Baskı, Ankara: Nobel Yayın Dağıtım, s. 15-7; 2002.

23. Tiggemann M, Williamson S. The effect of exercise on body satisfaction and self-esteem as a function of gender and age. Sex Roles. 2000;43(1-2):119-27.

24. Mollaoğulları H, Alptuğ EC. Spor yapan ve yapmayan üniversite öğrencilerinin benlik saygısı ve atılganlık düzeylerinin incelenmesi. Muğla Sitkı Koçman Üniversitesi Sosyal Bilimleri Enstitüsü Dergisi. 31:13543;2013.

25. Aşçı FH. Fiziksel benlik algısının cinsiyete ve fiziksel aktivite düzeyine göre karşılaştırılması. Hacettepe J Sport Sci. 2004;15(1):39-48.
26. Haff GG, Triplett NT. Essentials of Strength Training and Conditioning. 4th ed. Human Kinetics Australia; 2015.

27. Burgess G, Grogan S, Burwitz L. Effects of a 6-week aerobic dance intervention on body image and physical self-perceptions in adolescent girls. Body Image. 2006;3(1):57-66.

28. Jankauskienė R, Kardelis K, Pajaujienè S. Muscle size satisfaction and predisposition for a health harmful practice in bodybuilders and recreational gymnasium users. Medicina (Kaunas). 2007; 43(4):338-46.

29. Campbell A, Hausenblas HA. Effects of exercise interventions on body image: a meta-analysis. J Health Psychol. 2009;14(6):780-93.

30. İçten B, Koruç Z, Kocaekși Z. 6 haftalık egzersiz öncesi ve sonrası 12-15 yaş aralığındaki çocukların benlik saygısındaki değișim. 9. Uluslararası Spor Bilimleri Kongresi, Muğla; 2006.

31. Așçı FH. Benlik Kavramı ve Spor. Spor Psikolojisi Kursu. P Bayar (Der). Ankara: Bağırgan Yayınevi; 1999.

32. Kamal AF, Blais $\mathrm{C}$, Kelly $\mathrm{P}$, et al. https://www.cabdirect.org/cabdirect/search/?q=au $\% 3 a \% 22$ Ekstrand $\% 2 c+K . \% 22$ Self-esteem attributional components of athletes versus nonathletes. Int J Sport Psychol. 1995;26(2):189-95.

33. Pickett TC, Lewis RJ, Cash TF. Men, muscles and body image: comparisons of competitive bodybuilders, weight trainers, and athletically active controls. $\mathrm{Br} \mathrm{J}$ Sports Med. 2005;39(4):217-22.

34. Yegül IB. Liseli erkek sporcular ile sporcu olmayan bireylerin benlik saygısı ve atletik yeterlik puanlarının karşılaştırılması. Hacettepe Üniversitesi Sağlık Bilimleri Enstitüsü Yüksek Lisans Tezi. Ankara: Hacettepe Üniversitesi; 1999.

35. Çiçek G, İmamoğlu O, Yamaner F, et al. Kardiyo Bosu egzersizinin sedanter kadınlarda psikolojik etkileri. USEABD. 2017;3(3):69-75.

36. Yalman A. Sağlıklı genç olgularda yüksek yoğunluklu intervalli aerobik egzersiz eğitimi ile submaksimal sürekli aerobik egzersiz eğitiminin solunum fonksiyonları, egzersiz kapasitesi, stres düzeyi ve benlik saygısı üzerine etkilerinin karşılaştırılması. Pamukkale Üniversitesi Sağllk Bilimleri Enstitüsü Yüksek Lisans Tezi. Denizli: Pamukkale Üniversitesi;2016.

37. Karakaya I, Coşkun A, Ağaoğlu B. Yüzücülerin depresyon, benlik saygısı ve kaygı düzeylerinin değerlendirilmesi. Anadolu Psikiyatri Derg. 2006;7/3):162-6. 